\title{
Round 2: What Does Textile and Apparel Interdisciplinary Research and Education Look Like in the $21^{\text {st }}$ Century?
}

\author{
Summary of the Special Topic session \\ December 16, 2015 \\ Jung Ha-Brookshire, University of Missouri \\ Karen LaBat, University of Minnesota
}

This special session was held on Thursday, November 12, 2015, from 7:00-8:30 pm during the 2015 ITAA annual meeting in Santa Fe, NM. Approximately 40 ITAA members participated in this session. Many were not able to come to the session due to the late schedule of this session and other conflicting events. The majority of the session was dedicated to discussing five key Grand Challenges that the Sedona Group had previously identified. The five Grand Challenges were: (a) environmental sustainability (climate change, preservation, resource utilization, etc.) led by Linda Welters; (b) social sustainability (Corporate social responsibility, community development, poverty, etc.) led by Dee Knight; (c) health and well-being (obesity, mental health, body image, quality of life, disruptive technology, etc.) led by Nancy Rudd; (d) shifts in demographics (aging, immigration, diversity, etc.) led by Andrew Reiley; and (e) inequality (in gender, ethnicity, education, wealth, etc.) led by Minjeong Kim. Karen LaBat and Jung HaBrookshire led the group discussion using Art of Hosting (or Art of Participatory Leadership) techniques. The group discussed the specific issues, our strength, potential partners, and additional capacity we might need to help solve these problems. The participants' input and concerns were documented, resulting in a 7-page summary document. This document was shared with all participants who showed further interest in future activities.

Session Coordinator:

Jung Ha-Brookshire, University of Missouri

Karen LaBat, University of Minnesota

Sedona Group members:

Missy Bye, University of Minnesota

Jana Hawley, University of Arizona

Susan Kaiser, University of California-Davis

Rita Kean, University of Nebraska

Minjeong Kim, Oregon State University

Dee Knight, University of North Texas

Jaeil Lee, Seattle Pacific University

Yuri Lee, Seoul National University

Sara Marcketti, Iowa State University

Juyeon Park, Colorado State University

Nancy Rabolt, San Francisco State University

Andy Reilly, University of Hawai $i$ at Mānoa 
Eulanda Sanders, Iowa State University

Linda Welters, University of Rhode Island

Nancy A. Rudd, Ohio State University

Catherine Leslie, Kent State University

Casey Stannard, Louisiana State University

Chajuana V. Trawick, Lindenwood University 